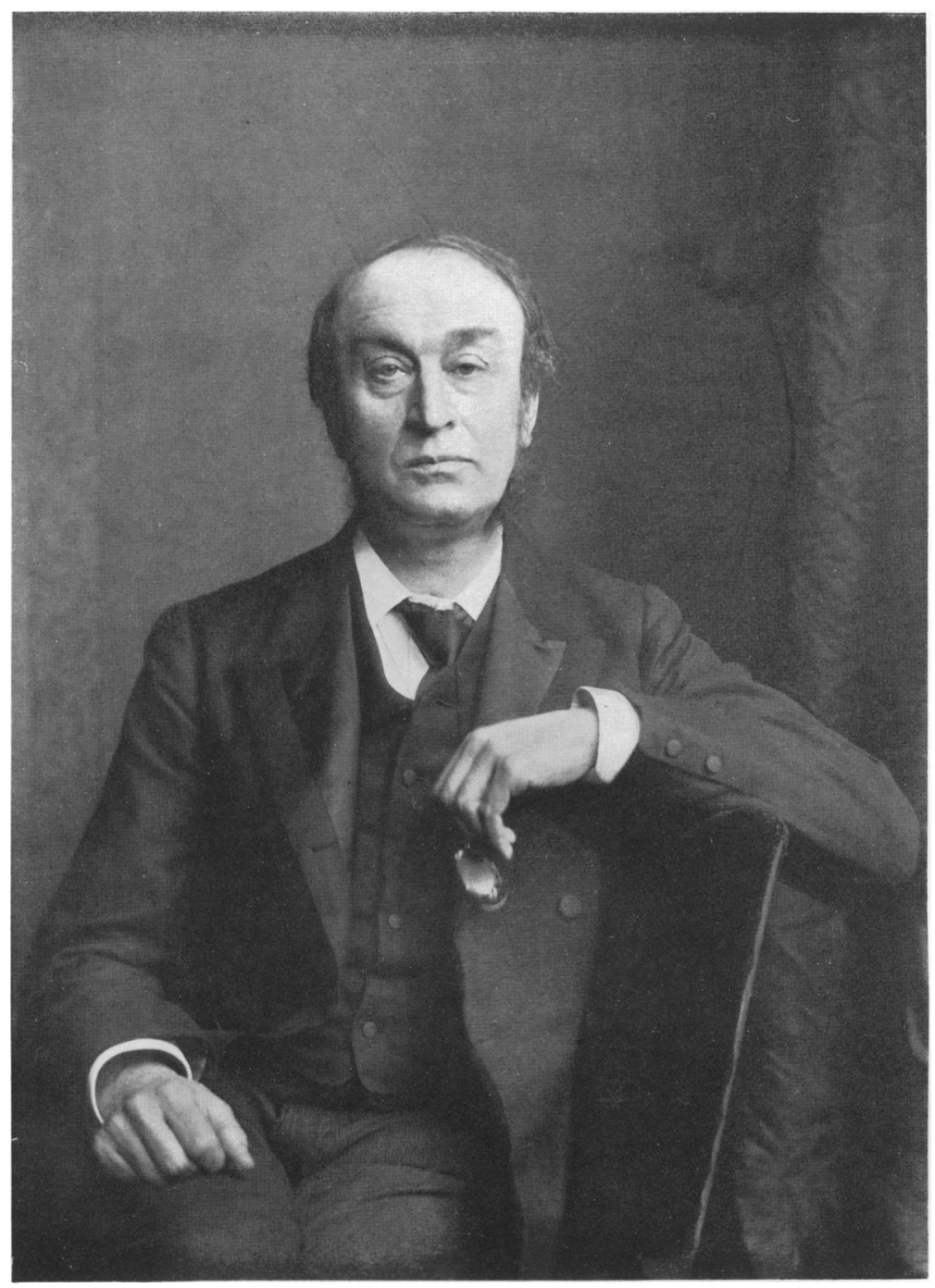

R. Faulkner \& Co., Photographers, 21 Baker Street. London.

\title{
SIDNEY RINGER
}




\section{IN MEMORY OF SIDNEY RINGER}

[1835-1910]

\section{SOME ACCOUNT OF THE FUNDAMENTAL DISCOVERIES OF THE GREAT PIONEER OF THE BIO-CHEMISTRY OF CRYSTALLO.COLLOIDS IN LIVING CELLS}

It is often notable, on consulting the original writings of masterworkers in any domain of knowledge, to what an extent these contain, crystallized out in single sentences, or short paragraphs, discoveries of great beauty or intense importance, which have afterwards been re-discovered and related at ream's length by subsequent writers.

This observation will strike anyone who cares to dive into the original papers of Thomas Graham on colloids, and it is no less striking in the writings of his colleague, Sidney Ringer, on the correlated subject of the crystallo-colloids and the balanced activities of the inorganic constituents in regulating and controlling the energy discharges of living cells.

Both physical chemists and bio-chemists have nowadays come to realise that the most fruitful ground of both chemistry and biology lies in the land of colloids, and of colloidal and crystalloidal relationships. It is a remarkable fact that the master-discoveries in these two closely related domains belong to two men identified with the same institution, who, keen though they were over their experiments, dimly, if at all, realised the vast extensions which lay before their discoveries. Graham does appear to have dimly seen that there was a relationship between the energetics of the colloidal state and the life processes of cells, and draws attention to the fact that colloids are unstable and all the time suffering slow energy changes, while crystalloids are inert and inactive in stable equilibrium.

Ringer equally appreciated the importance of the inorganic salts in living processes, in stimulating or stilling muscular activity, or in varying the velocity of growth and repair in living cells of all types. 
But the state of advancement of knowledge at the time the discoveries were made precluded either observer from surveying the whole field and seeing how much all these researches were complemental to one another, and that the ultimate substrate for the energy display was the delicately balanced equilibrium between colloid and crystalloid.

Ringer's researches, which yield such a magnificent demonstration of the applicability of the fundamental principles of the ionic theory, were made independently of it, and before it had gained any general acceptance. Accordingly, one can only marvel now at the experimental inspiration and clear logical following out of sequences which enabled him to develop one fact after another, track out one possibility after another, and eliminate everything extraneous until he had found the true connection between the phenomena with which he was dealing.

Remarkable accuracy in observing detail, thoroughness in investigating every factor in the problem, however trivial at first sight that factor might seem, and untiring energy in repetition of experiment until he was quite certain he held the whole truth of the case without omission or exaggeration, were the traits which went to make up Ringer's character, both as a scientific observer in the laboratory and as a clinician in the hospital. At the active period of his scientific work he .was a most prolific writer, yet all his work, so far as he was responsible, has stood the test of time and grown in beauty in men's eyes with the lapse of the years.

In one of his later conceptions only was Ringer misled by a circumstance over which he had no control. The laboratory supply of distilled water contained an unsuspected impurity, viz., a trace of copper, due to a defect in the still, and this misled Ringer as to the action of the supposed pure distilled water upon living organisms. The writer happened at the time to be working in collaboration with him at another piece of work, and, at his request, tested the laboratory water; he can still well remember Ringer's chagrin and disappointment when the presence of copper in the water was demonstrated to him. This incident, although he could not possibly have foreseen it, troubled him not a little; he temporarily ceased work upon his beloved subject, and other events which meanwhile occurred in private life conspired to prevent him ever afterwards taking up laboratory work with his wonted energy, so that he never contributed further to the subject, with the 
exception of a short note to the Physiological Society, published about two years later. ${ }^{1}$

The first of the remarkable series of papers which record Ringer's discoveries of the actions of inorganic salts (or ions). upon the beat of the heart, is contained in the third volume of the Journal of Physiology, 1881-2, under the title 'Concerning the influence exerted by each of the Constituents of the Blood on the Contraction of the Ventricle.' This first paper demonstrates clearly Ringer's scientific insight and doggedness of purpose. He shows that certain changes in the ventricular beat, which, at this stage, he thinks are due to normal saline $(0.75$ per cent. solution of sodium chloride), but which in a later paper he finds out are due to a trace of calcium salt in the supply of New River Water with which the saline has been made up-he shows that these changes can be obviated if a certain amount of dried blood is added to the saline. Proceeding further, he finds that diluted white-of-egg added to the saline produces a like result in maintaining the normal heart-beat. The ordinary investigator would probably have stopped here, thinking he had done well and probed matters to the limit. Not so Ringer, and this is precisely how he made the first step that counts so much towards his great discovery. Having discovered that both dried blood extract and diluted egg-white act upon the contracting rentricle, he does not jump to

1. This note takes up the matter of the supposed action of distilled water on Tubifex, and is characteristic of Ringer, both in its carefulness and exactitude and in the candour and honesty with which it admits the truth of Locke's position : that the supposed poisonous and disintegrating action of distilled water obtained by distillation from a metal still and condenser are due to infinitesimal traces of heavy metals in the water. He first of all re-distilled from glass thirty litres of the type of water used originally with poisonous effects, and now found the distillate harmless, and the residue to contain copper and be violently poisonous until after exposure to air for some days. Then he collected Nature's own distillate in the form of rainwater on his Yorkshire moorside in earthenware vessels, and demonstrated that this water was harmless to the organisms although it contained no trace of calcium salts. On placing a few small pieces of copper filings in this innocuous water it became poisonous and disintegrated 'Tubifex in a few hours. As a result of this careful enquiry he frankly admits that: - These experiments appear to me to establish Locke's conclusion that copper in even infinitesimal quantities will disintegrate Tubifex, whilst water free from copper or other heavy metals, and without any salts such as calcium salts, can sustain the life of 'I'ubifex.' In spite of this disappointment it is interesting to observe Ringer's mental activity in seizing the opportunity to demonstrate to the hilt the most important fact which he had earlier observed as to the antagonism of the potassium and calcium effects. He says, "I next tested with this rainwater from the moors the antagonism between potassium chloride and calcium chloride. I placed Tubifex in a $0 \cdot 1$ per cent. solution of potassium chloride, in about four hours they were almost motionless, and with the microscope I was unable to see the vessels contract; they appeared quite paralysed except just below the head of the animals. I then placed the Tubifex in a 0.1 per cent. KCl and 0.1 per cent. $\mathrm{CaCl}_{2}$ and almost at once spontaneous movement increaseá, and in five minutes they became quite active. Seven hours later they were moving energetically; before movement was so much restored the microscope showed that the vessels, even to the tail were contracting vigorously.' (Proc. Physiol. Soc., December, 1897, Journ. of Physiol., Vol. XXI, pp. 14, 15.) 
what, at that stage of our knowledge, would be the most obvious conclusion, viz, that this common good result arose from the nutrition of the contracting ventricle by the proteins common to both fluids. Here are the discoverer's own words on the subject:- 'Blood, then, obviates the changes occurring in the contractions of a ventricle receiving only saline solution, and the question arises, which constituent of the blood has this property:

'I find that a small quantity of white-of-egg completely obviates the changes occurring with saline solution. I first took tracings with blood mixture; I then replaced the blood with 100 c.c. of saline, and got the usual great prolongation of dilatation. I then added to the saline 25 c.c. of white-of-egg mixture, composed of one part white-of-egg in two parts of water. In two minutes the rontractions became exactly as they were when the heart was supplied with blood mixture. White-of-egg consists of albumins and chloride of potassium and sodium, chiefly rhloride of potassium. It is obvious in the preceding experiment that the effect of white-of-egg rould not be due to the sodium chloride. The power to obviate the great prolongation of the dilatation occurring when the rentricle was supplied with saline solution must, then, be due to the albumins or the potassium chloride.'

'I find that potassium chloride in small quantities, much smaller than exists in serum, will completely and speedily obviate the rharacter of the trace occurring with saline solution, and give a trace in all respects like that occurring when the ventricle is supplied with blood mixture.' [References to the tracings here.] 'I first took a tracing with blood mixture, and then replaced the blood with 100 c.c. of saline solution. After about 15 minutes I obtained the usual great prolongation of the ventricular dilatation. I then added to the $100 \mathrm{cec}$. of circulating saline $0 . \tau$ c.c. of 1 per cent. solution of potassium chloride at the point indicated by the arrow; very speedily the contraction became modified, the dilatation becoming much shorter. Ten minutes after the addition of the potassium chloride the contraction became just like those at the beginning of the experiment when the ventricle was supplied with blood. From numerous experiments, I find that from $0 \cdot 6$ c.c. to 1 c.c. of 1 per cent. solution of potassium chloride to the 100 c.c. of saline solution is sufficient to remove the prolongation of dilatation occurring with saline solution.'

At the date of this paper the ionization theory of Arrhenius had not yet appeared on the scientific horizon, and hence it is most interesting to 
observe Ringer, in complete ignorance of it of course, proceeding to accumulate evidence in strong support of it had it only been known later to the supporters of the theory in their days of battle.

In the same manner, as recounted in his own words above, Ringer proceeded to test the actions of phosphate of potash and phosphate of soda (as he calls them), and found that phosphate of potash had precisely the same action as potassium chloride, while phosphate of soda had no action. His conclusion is that, 'the effect, then, in potassium phosphate is due to the potassium and not to the phosphoric acid.'

'Probably any potassium salt is sufficient to obviate the prolonged dilatation occurring when the ventricle is fed with saline solution only, for I have produced normal contractions by adding to the saline solution potassium chloride, potassium phosphate, potassium sulphate, potassium citrate, potassium bi-carbonate, potassium chlorate, potassium nitrate, potassium acetate, and potassium carbonate.'

Throughout this paper Ringer is ignorant of the fact that the prolongation of ventricular relaxation antagonized by the potassium salts is due to the presence of an unbalanced trace of calcium salt in his saline solution. It is a remarkable piece of scientific good fortune that this accident had occurred, for although the diminution in force of beat and stoppage in pure distilled water plus sodium chloride is characteristic enough as compared with the full 'Ringer's effect' as now known to us, yet any such slowing down without the long tailing off produced by unbalanced calcium ion would probably not have attracted Ringer's attention in these earlier days, or called forth his energies to the same extent.

In his next paper, however, in the fourth volume of the Journal of Physiology, ${ }^{1}$ he has discovered the great influence of minute traces of calcium upon the heart. Previous work of his own and of others upon the antagonistic action upon the heart of different alkaloids had prepared his mind, and the thought of an antagonism, as he calls it, between calcium and potassium fell upon prepared ground. In this second paper he clearly shows how different inorganic constituents can balance or antagonise one another, and this is reiterated in paper after paper of the succeeding members of the long series, and upon one type

1. The papers are not dated in these earlier volumes of the Journal of Physiology, and it is somewhat difficult to accurately assign dates; the paper immediately preceding Ringer's is dated November, 1882, so the date must be the end of 1882 , or early in 1883. A later reference given by Ringer himself in Vol. XVI of the Journal of Physiology places these earlier papers in 1883 (See Journ. Physiol., Vol. XVI, p. 1). 
of material after another, such as ventricular muscle, skeletal muscle, growing frog's eggs, tadpoles, small fishes, tubifex worms, and so on. It is indeed remarkable that any man should have so reiterated and driven home a discovery of such first-rate importance, himself recognising its great value, although naturally he did not realise its more modern extensions, and that then for years he should be almost unknown in connection with it, save perhaps as the inventor of ' Ringer's solution.'

The description, in the discoverer's own words, of how he came upon the calcium effect is highly interesting. He says:- 'After the publication of a paper in the Journal of Physiology, Vol. III, No. 5, entitled "Concerning the influence exerted by each of the Constituents of the Blood on the Contraction of the Ventricle," I discovered that the saline solution which I had used had not been prepared with distilled water, but with pipe water supplied by the New River Water Company. As this water contains minute traces of rarious inorganic substances, I at once tested the action of saline solution made with distilled water, and I found that I did not get the effects described in the paper referred to. It is obvious, therefore, that the effects I had obtained are due to some of the inorganic constituents of the pipe water.'

He then quotes a detailed analysis of New River Water, showing that amongst other things it contains $38 \cdot 3$ parts in a million of calcium, and proceeds experimentally to investigate calcium effects upon the ventricle. He shows that saline made from distilled water with pure sodium chloride does not give the rounded top and slow tailing off, but only shows a gradual cessation of activity altogether; then he adds a trace of calcium salt and obtains the now well-known result previously given by the New River Water saline. Further addition of the necessary small amount of a potassium salt takes away the slow relaxation and gives a normal beat which does not diminish and cease like that in presence of sodium chloride only, but remains strong and good for hours. After much experimentation and elimination or due appraising of actions of different constituents, Ringer describes the separate and combined effects as follows:-

'The heart's contractility cannot be sustained by saline solution, nor by saline containing potassium chloride, nor with saline solution containing bicarbonate of soda, nor by saline solution containing bicarbonate of soda and potassium chloride; but after contractility has ceased, the addition of a lime salt will restore good contractility. The addition, too, of a calcium salt to any of the above solutions will sustain 
contractility. I conclude, therefore, that a lime salt is necessary for the maintenance of muscular contractility.' 'But while calcium salts are necessary for the proper contraction of the heart, yet if unantagonised by potassium salts the beats would become so broad and the diastolic dilatation so prolonged that much fusion of the beats would occur and the ventricle would be thrown into a state of tetanus.' 'As the ventricle will continue to beat perfectly for hours without any sodium bicarbonate, it is evident that the normal trace is the result of the antagonising action of calcium and potassium salts.' 'If these two salts [we should say ions at the present day] are not present in the correct proportions, then the trace becomes abnormal. If too little potassium is present, the contractious become broader, etc., and there results fusion of the beats. If too much potassium is present, or too little lime salts, then the contraction of the ventricle is imperfect, and by increasing the quantity of potassium salt the beat becomes weaker and weaker till it stops.' 'As the heart will continue to beat quite normally for hours without albumen or haemoglobin, it is obvious that these substances are not immediately necessary for contraction, but of course they are necessary to reconstruct the tissues from the loss due to contractions.'

In these few sentences we have the whole law and gospel of the action of inorganic constituents on contractile tissue, and since then there has been chiefly adding of detail. A great deal of detail was added in this and later papers by Ringer himself, and he demonstrated the same relationship in the excitation of rhythmic contractions in skeletal muscle and their inhibition by the antagonistic salts. In the next paper Ringer tests the effects of an excess of potassium salts, and finds that the latent period is greatly prolonged, and also the period of diminished excitability, so that the frequency of beat becomes diminished. In this paper also he points out a remarkable change to faradic stimulation of the ventricle induced by potassium. In absence of any excess of potassium, faradization calses a fusion of beats in a contracted or systolic condition which Ringer, following Marey, speaks of as tetanus; in presence of an excess of potassium there is a reverse action, for now faradization completely arrests the contractions which recommence on discontinuing the faradization.

Rubidium in all respects acts similarly to potassium, but the higher member of the alkali group, viz., caesium, possesses a quite different action.

' Caesium, indeed, produces for the most part the opposite effects to 
potassium, broadening the trace, rounding its top, inducing fusion; yet in spite of this great difference in its action, still caesium, like potassium, possesses the property of obviating the effect of calcium on the dilatation.' He finds that calcium and caesium make a fairly good balance; but strontium and caesium will not make a good working pair. Strontium and potassium work; but not barium and potassium. The separate action of caesium resembles that of barium, but barium and calcium do not balance as do caesium and calcium.

' It is interesting to compare the effect of chemical similarity on physiological similarity in the group calcium, strontium, and barium, and in the group including potassium, rubidium, and caesium.'

'Strontium is chemically more allied to calcium than barium is to calcium, and whilst strontium is in its physiological action very similar to calcium, barium is far less similar to calcium. So it is with the group potassium, rubidium, and caesium. Rubidium is chemically more allied than caesium to potassium, and rubidium is almost identical in its physiological action with potassium, whilst caesium differs in most of its physiological effects from potassium.'

The effects of saline media on fishes are discussed in a communication to the Physiological Society in December, 1883, and in a most interesting paper appearing a few months later in the Journal of Physiology (Vol. V, p. 98). In these researches much interesting matter is brought together as to the behaviour of both fresh-water and salt-water fish when subjected to variations in the salinity of the medium in which they are living. It is demonstrated by Ringer that even fresh-water fish, such as minnows and sticklebacks rapidly perish when kept in distilled water, ${ }^{1}$ and the effects of variations in oxygen supply being ruled out by experiment, it is shown that sodium, potassium and calcium salts are necessary to life in water. He shows that calcium in small amounts greatly prolongs life in distilled water, and that additional increase of longevity is obtained when sodium carbonate and potassium chloride are also added.

The concentration of calcium necessary for the sustenance of life is very low, but this can be exceeded manifold without causing the death of the fish; thus, as much as 0.5 per cent. of calcium chloride in the water could be borne by minnows.

In the next paper Ringer proceeds to examine the effects upon heart

1. In view of later discoveries it would now be of interest to repeat these earlier experiments of Ringer on the action of distilled water on organisms. 
muscle of large toxic doses of calcium and potassium in the unbalanced and balanced conditions, and shows that a dose of either salt (or ion) which would be many times sufficient to poison the rentricle can be borne without ill effects when balanced by its antagonist. The paper might rank as a study of a balanced reaction at the present day, now about twenty-six years later. The whole subject illustrates the balancing of toxin and anti-toxin, as shown with inorganic ions. The calcium and potassium ions do not unite in stochiometric relationships with one another; in fact they have no appreciable chemical affinity for each other; but both are claimants for the bio-plasm of the ventricular muscle-cells, and in proper proportions determined by their chemical coefficients for the bio-plasm, we get balancing and the to-and-fro beat of the heart. This ratio can evidently exist at many corresponding concentrations of potassium and calcium, but a balance must be maintained. To each concentration of either of the two, there is a short range within which the other ion must lie.

The next paper, also in the fifth rolume of the Journal of physiology, demonstrates that reratria behares similarly to calcium upon the heart rentricle, and can even replace lime salts, though somewhat imperfectly. The interesting fact is also shown that reratria and potassium, just like calcium and potassium, are mutually antagonistic.

In a second paper, dealing also with veratria and potassium, Ringer attempts some analysis of the different molecular reactions, as he terms them, occurring during contraction, relaxation, and reparation in the rentricular tissue. His words show a remarkable insight for the period at which they were written, and historically are worthy of quotation.

'In a muscular contraction three distinct forms of molecular change are obvious; namely, the changes occurring during the latent period, the changes which occur during contraction, and the changes causing the dilatation.' 'Those molecular changes which lead to dilatation are generally considered restorative or reparative; they prepare new material for the ensuing contraction, or remore waste products which would retard or prevent contraction; or they consist of both of these processes combined.' 'The independence of those molecular changes which occur at the termination of a contraction (and which cause dilatation) from the reparative changes is well shown by the action of lime on the ventricle. Calcium chloride, added to saline solution, greatly delays dilatation, but does not in any degree delay the reparative changes, so that no matter at 
what period the excitation is made, the succeeding contraction is complete, even though the excitation is applied before dilatation is finished. Here, then, we have a drug which, like veratria, retards those molecular changes that lead to dilatation, but, unlike veratria, in no degree lessens the rapidity of the reparative changes.'

'We have seen that both veratria and potash salts retard the reparative changes, veratria more so than potash, and yet when these substances are both added to the circulating fluid they do not in this respect intensify each other's action, but distinctly antagonise each other, the reparative changes occurring much more rapidly after the addition of potash to the veratrized circulating fluid. We have, then, another instance of drugs having a common action, and yet when both are conjointly added to the circulating fluid, one antagonises the other in respect of this common effect.'

In a somewhat lengthy paper entering into a discussion of contemporary continental opinion as to whether organic nutrition is directly necessary to the heart-beat, Ringer attempts to separate all salts by dialysing albumin solutions, but finds it impossible to get rid of the calcium which adheres after prolonged dialysis. He then shrewdly suspects what we now know to be the correct view, that it is this strongly adherent calcium which enables albumin solutions to keep up contractions without the addition of inorganic calcium salt.

The next contribution is a most interesting one on the effect of lime salts upon the absorption of water by laminaria and other organic structures. It is full of interesting observations, the details of which cannot be entered upon here; but it is well worthy of perusal to-day by anyone interested in the modern problems of absorption of salts by colloids.

In a set of three papers following rapidly on this, Ringer demonstrates most clearly the action of calcium and other ions upon skeletal muscle. The first of the series is by Ringer alone, and in it the muscle is simply immersed in the various saline solutions. In a later paper, in collaboration with Dudley Buxton, the similar effects are described which are obtained when the various solutions are perfused from the aorta.

These papers are of great historic interest to all students of the action of inorganic ions on living cells, and since Ringer's connection with this work appears to have been well nigh forgotten, some recognition may here be made by quoting his main findings from the 
earlier paper, and reproducing certain of his tracings. ${ }^{1}$ The paper is contained in the Journal of Physiology, Vol. VII, pp. 291-308, 1886. It is noteworthy that it was here that Ringer first commenced to use calcium phosphate in his circulating fluid, having previously used chlorides only of sodium, potassium and calcium, that is up till this stage, he had himself always used what is now a modern modification of Ringer's solution. It is also of interest that his calcium phosphate, as he tells us, was analysed for him by his colleague Dr. Graham, Professor of Chemistry at University College. After exhaustive experiments on the periods during which skeletal muscles kept in various saline combinations retained their direct faradic excitability, he classifies them in the following order and then proceeds to describe his experiments on the contractions of skeletal muscle in saline solutions :-

'We see then that these solutions in respect of their efficiency to sustain contractility stand in the following order. Saline solution is the least effective, next follows saline containing sodium bicarbonate, then phosphate of lime saline, next phosphate of lime saline containing potassium chloride. Phosphate of lime saline containing potassium chloride and phosphate of lime saline containing potassium chloride and sodium bicarbonate sustain contractility about an equal time. Phosphate of lime saline sustains contractility longer than saline solution containing sodium bicarbonate.'

'Now this being the order of their efficiency as circulating fluids for the heart, it would appear that lime and potash salts are as necessary to the metabolism of muscle at rest as to the metabolism occurring during a muscular contraction.

Another circumstance however explains in part the efficacy of lime and potassium salts in sustaining contractility in quiescent muscle.

I noticed in the muscles placed in saline active contractions. This was much more apparent in muscles that were partially detached, and especially noticeable in the sartorius when torn from the rest of the muscles and attached only by its lower end. Now these contractions must consume the energy of the muscles and hasten exhaustion and the advent of rigor mortis.

- In February I commenced a further series of experiments regarding the effect of saline solution and saline solution containing other salts to produce contractions.

1. For permission to make these copious extracts, and to reproduce the accompanying traces, the thanks of the writer are due to Prof. J. N. Langley, the Editor of the Journal of Physiology. 
Since I made these observations I find that Biedermann ${ }^{1}$ has made similar experiments with results quite in accord with mine. Our methods however differed in some respects, and I recount here certain additional experiments to those he performed.

In his experiments he employed the sartorius of a strongly curarized frog. He suspended the muscle in a solution consisting of a litre of water, 5 grams $\mathrm{NaCl}, 2.5$ grams $\mathrm{Na}_{2} \mathrm{HPO}_{4}$, and 0.4 gram $\mathrm{Na}_{2} \mathrm{CO}_{3}$, and in most of his experiments he kept the temperature below $10^{\circ} \mathrm{C}$. He obtained contractions in all respects like those described in my experiments, but I employed all the muscles of the thigh cut into thin ribands and attached only at the knee. I did not curarize the frog and I placed the limb in simple saline. Biedermann took no tracings of the contractions.

It is obvious therefore that the alkaline soda salts do not play so important a part in the production of these contractions as Biedermann supposes. I shall show that phosphate of soda or caustic soda added to saline increases somewhat the frequency and the strength of the contractions. As I have said though working under different circumstances I obtain the same results, so well described by Biedermann.

We both find that temperature strongly influences these contractions, these being more frequent and more vigorous at a temperature between 20 and $30^{\circ} \mathrm{C}$. than below $10^{\circ} \mathrm{C}$. At a low temperature the contractions become somewhat rhythmical. There occur long pauses free from contractions, varying from ten seconds to two or three minutes, and then a series of contractions take place of much the same strength and separated by about the same intervals. Occasionally the beats for a minute or two are quite rhythmical.

I cut off both hind limbs of a frog through the hip joint and after stripping off the skin I cut the thigh muscles into thin ribands, and left them attached only at their lower end close to the knee joint. One limb I suspended in 200 c.c. 6 per cent. saline solution, the other in a similar quantity of saline solution containing some other salt.

On placing the limb in saline solution the strips of muscles at once contract frequently, and one sees both massive and fibrillary contraction, i.e., the whole muscle or piece of muscle is contracted, and in addition one sees the contraction of fibrillae merely. The contractions begin soonest and are most marked in the thigh muscles cut into thin bands. Later fibrillary contractions occur in the uninjured lower leg muscles causing

1. Wien. Sitzungsbericht. Bd. Lxxxı, 1880, p. 257. 
twitching of the toes. These contractions persist often for hours and continue longer in the uninjured than in the thigh muscles cut into ribands.

As Biedermann noticed with his solution so I find that when the contractions have ceased they often recur on renewing the saline solution.

On removing the limb from saline, strong fibrillary contractions persist for some time, and when they cease the excitation of a contraction by the faradic current brings them back again to persist without any further stimulation for half a minute or even longer.

The muscles of the fellow limb placed in phosphate of lime saline solution twitch much less, and in some cases no contractions at all occur.

The addition of 1 c.c. of 1 per cent. solution of potassium chloride to each 100 c.c. of the testing fluid very slightly lessens the fibrillary twitching of the muscles in saline solution. The twitchings of the muscles in phosphate of lime saline solution are greatly lessened or even utterly arrested; but on replacing the muscles in their original fluid the twitching again increases, and on the further addition of potassium chloride the same effect follows as on the first addition.'

' I find that small doses of potassium chloride 1 c.c. to 4 c.c. of 1 per cent. solution added to 100 c.c. of saline somewhat lessen the contractions. These quantities added to phosphate of lime saline solution at once check any movements, though, as I have said, phosphate of lime without the aid of potassium chloride generally prevents any movements.'

'Saline made with tap water prevents these twitchings, as the following experiment proves.

On Jan. 20 I placed one posterior extremity in 200 c.c. distilled water saline, the other in 200 c.c. tap water saline. The muscles in the distilled water [saline] began to twitch in three minutes and in ten minutes became quite brisk, the lower leg muscles quivering actively as well as the partially detached muscles of the thigh. The twitchings continued all day and were quite energetic eight hours from the beginning. The muscles in tap water saline did not twitch at all.

Contrary to what one would expect distilled water causes few or no twitchings.

On Jan. 20 I placed one hind limb of a frog in 200 c.c. distilled water saline and the other in distilled water. Active twitching persisted in the muscles in saline solution three hours, but had ceased in five hours and a half. In the muscles in distilled water one twitch 
occurred five minutes after the immersion but no other movement, and all the muscles soon passed into firm rigor.'

'Mere alteration in the percentage amount of salt influences the contraction, as the following experiment shows. On April 13 I placed the sartorius in 0.5 per cent. saline solution. For the first three minutes only the faintest contractions occurred. They then for two or three minutes became moderately strong and again grew weak. I then added 25 c.c. 2 per cent. solution of salt to 200 c.c. of 05 per cent., which much increased the activity of the contractions. I then returned to 0.5 per cent. solution and in about a minute the contractions became much weaker. I then added 25 c.c. of 2 per cent. solution to 150 c.c. of 0.5 per cent. solution and the contractions became greatly increased. I added another 25 c.c. of 2 per cent. solution and still further increased the contractions. Again I returned to 150 c.c. of 0.5 per cent. solution and the contractions greatly lessened, occurring in paroxysms with quiescent periods of half a minute. I then added 50 c.c. 2 per cent. solution, and again greatly increased the frequency of the contractions. On returning to 150 c.c. of 0.5 per cent. solution contractions ceased but returned for a short time on adding 50 c.c. of 2 per cent. solution of sodium chloride.

On the other hand, lessening the relative amount of $\mathrm{NaCl}$, as by adding distilled water to the saline solution lessens or prevents these muscular contractions. For instance, reducing the 0.6 per cent. to 0.5 per cent. NaCl decidedly lessens the contractions. Here I will record one experiment showing the effect of dilution. I first took a trace with 200 c.c. 0.6 per cent. saliue solution, and obtained active contractions. On adding 50 c.c. distilled water, the contractions ceased and failed to return on adding another 50 c.e. and a third 50 c.c. distilled water. On returning to 0.6 per cent. saline, slight contractions recommenced, and the further addition of 2 c.c. of 2 per cent. $\mathrm{BaCl}_{2}$ induced active coutractions.

I next tested the effect simply of distilled water on the contractions. I first took a trace with $0 \cdot 6$ per cent. saline solution, and then replaced this by distilled water, when the contractions ceased at once, though in some experiments a few single strong contractions occurred at many minutes' interval. The distilled water however induced some persistent contraction, which passed away on the addition of saline, provided not too long a term had elapsed, before adding the $\mathrm{NaCl}$, i.e., about eight to ten minutes.

When these contractions brought out by immersion in saline cease 
contractility still persists, and stimulating the muscle with a faradic current the coil, standing at 15 to 20 , will excite good contractions. Moreover, the addition of substances like barium chloride at once developes active contraction; indeed barium chloride will produce contractions and persistent spasms much more marked than with saline at the beginning of the experiment.'

'I made twelve experiments to test also the effect of calcium chloride using 1 per cent. solution. I added 2 to 4 c.c. of this to 200 c.c. of saline solution. After testing the effect of simple saline I added at once 4 c.c. of calcium chloride solution. In every instance I tried this solution it almost immediately to a great extent lessened the contractions, and in many instances all but arrested them, in some, quite stopped them. In several cases after a few minutes slight contractions returned but were much less than with saline at the beginning of the experiment. In eight of the experiments at one period after the addition of lime chloride the contraction became literally rhythmic, i.e., the contraction occurred at pretty equal intervals and in much the same force. The following short account of an experiment is a good example of the experiments. On April 5 the sartorius in saline contracted actively. The addition of 4 c.c. of $\mathrm{CaCl}_{2}$ solution at once almost arrested the contractions which were rhythmic in character. I then returned to saline solution, which induced active contractions, and these were at once arrested on the addition of 4 c.c. of calcium chloride solution. Again I placed the muscle in simple saline and again active contractions occurred, which were at once arrested on adding 4 c.c. of 1 per cent. solution of potassium chloride.

The addition of lime chloride arrests not only the rapid contractions but also removes the persistent contraction, so that the trace rises higher above the base line. These effects are shown in fig. 3 .

In many experiments made with potassium chloride I find its action is largely influenced by temperature. My experiments have been made generally with the fluid at from $10^{\circ}$ to $16^{\circ} \mathrm{C}$. Soon after adding 4 c.e. of 1 per cent. solution of $\mathrm{KCl}$ to 200 c.c. saline solution the muscle strongly contracts, dragging down the recording lever far below the level reached even when the contractions are well marked with saline; the muscle then slowly relaxes, but before it has much elongated fresh contractions set in, or when at its maximum contraction frequent well marked contractions occur, and these cease and the muscle slowly relaxes, see fig. 4 . Then the muscle remains quiescent for a variable 


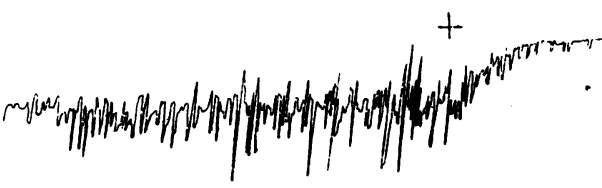

Fig 3

'Shows the effect of saline. At the cross 4 c.c. 1 per cent. $\mathrm{CaCl}_{2}$ were added to 200 c.c. saline.'

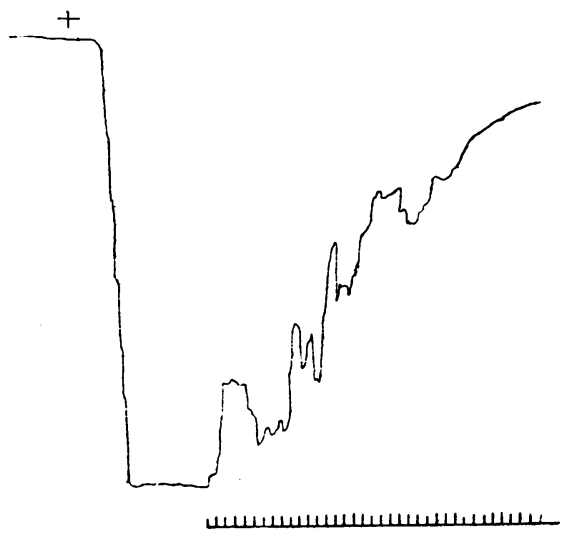

Fig 4

' Effect of adding 4 c.c. 1 per cent. solution of $\mathrm{KCl}$ to 200 c.c. saline solution added at the point indicated by a cross.'

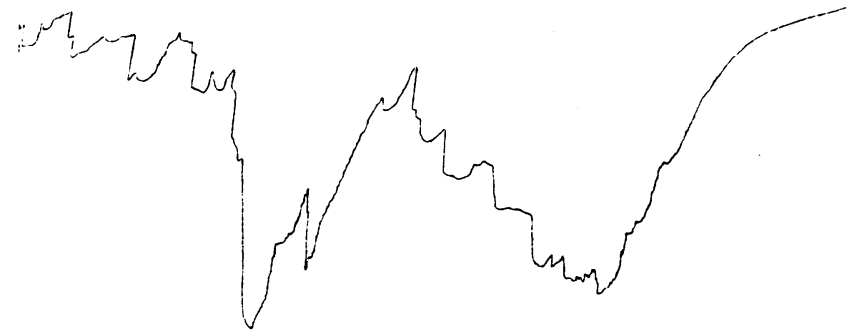

Fig 5

' Later effect of potassium chloride.' 
time, ten seconds to one or two minutes, when contractions like those recorded in fig. 5 occur and again the muscle becomes quiet, or after a few minutes again contracts as shown in the figure. By degrees the contractions become less marked and at last merge into a single slight contraction which relaxes slowly. With some muscles only these slighter contractions occur throughout the experiment. With a higher temperature the addition of potassium chloride solution, just like calcium chloride at once arrests the contractions. 1 c.c. of 1 per cent. solution diminishes the contractions greatly, but 2 c.c., i.e., 1 part of $\mathrm{KCl}$ in 5000 well-nigh stops them or stops them altogether, and on returning to simple saline solution the contractions recommence actively.

The following experiment is a good example of the influence of potassium chloride. On Feb. 26 a sartorius muscle placed in saline contracted energetically. To the 200 c.c. of saline I then added 2 c.c. of 1 per cent. solution of potassium chloride and the contractions all but ceased. Again I placed the muscle in 200 c.c. of saline solution and active contractions returned. I again added 2 c.c. of potassium chloride solution and again greatly restrained thie contractions, yet a third time saline solution restored the contractions, and this final trial stopped the contracting. In the previous experiment the changes were made quickly, but after the addition of 4 c.e. of potassium chloride solution to 200 c.c. saline solution, if the effect is watched for a considerable time, it generally happens that after an interral of two or three minutes contractions return, but occur in groups, a long interval often intervening. 'I'he contractions are often very vigorous and rapidly repeated; these outbursts of contractions at long interrals grow weaker and then cease. In some cases the trace is in the form of an irregularly wary line.

Potassium chloride then whilst modifying considerably the character of the contraction induces very marked contractions, and our previous experiments showed that potassium chloride added to saline solution does not sustain contractility. The difference between calcium chloride and potassium chloride is very striking, as the following experiment shows. On May 6 saline solution excited actire contractions, which were at once cut short on adding 4 c.e. of 1 per cent. solution of calcium chloride to 200 c.c. saline. After six minutes I replaced the sartorius in saline and soon after added 4 c.c. of 1 per cent. solution of potassium chloride. This produced the effect shown in fig. 5. I added 4 c.c. $\mathrm{CaCl}_{2}$ solution and at once stopped all contractions. In about four minutes I replaced the muscle in saline without inducing any strong contractions, as generally 
happens when saline solution replaces saline solution containing potassium chloride 1 part in 5000 . Soon afier I added 4. c.c. potassium chloride solution and again induced the usual potash effect, which was arrested again though more slowly by adding 4 c.c. of calcium chloride solution. I then again reverted to simple saline without inducing any contractions and again added 4 c.c. potassium chloride solution and induced well-marked potash contraction. These were again stopped though not so rapidly as on the first occasion by adding 4 c.c. of calcium chloride solution. Again I returned to saline, then added potassium chloride solution and again excited well-marked potash contractions, which calcium chloride once more arrested. This action of potassium chloride and the antagonism of calcium chloride I many times verified.'

In the later paper with Buxton it is shown that perfusion of the skeletal muscles with ordinary saline leads to similar contractions to which calcium salt acts again as a sedative. Skeletal muscle was found to differ from cardiac muscle in that, without any addition of calcium salt to the perfusing fluid, the period of relaxation became enormously prolonged, so that the trace became like that obtained from a veratrized muscle. Also, it was found that perfusion with sodium chloride saline alone very rapidly rendered the muscle inexcitable to direct faradization, but that excitability was restored on adding a calcium salt to the perfusing fluid.

Ringer's discoveries on the action of calcium salts upon contractile tissues and living organic processes in general led him to take a great interest in the studies of Hammarsten and J. R. Green on the action of the calcium salts in the coagulation of blood and milk, and to confirm and extend such observations in several important aspects. He showed that this favourable action of calcium salts was a generic property shared in feebler measure by the other members of the calcium group, and that it was to a certain extent antagonised by sodium and potassium, although this antagonism is but a feeble thing compared to that existing in living tissues. He also investigated the action of calcium salts upon metacasein and alkali albumin, showing that, following in exaggerated measure the general rule for inorganic calcium salts, the protein calcium salts are much less soluble at higher temperatures. These papers on the action of calcium upon coagulation contain much interesting material, and many valuable suggestions; they are contained in the Journal of Physiology, Vols. XI-XIII.

In the years 1894 and 1895 , Ringer, in collaboration first with 
Sainsbury, ${ }^{1}$ and later with Phear, ${ }^{2}$ studied the action upon Tubifex rivulorum, and upon growing tadpoles, of various saline constituents, and although the results contained in these papers, in so far as the supposed disintegrative action of distilled water is concerned, were vitiated, as demonstrated soon after by F. S. Locke, ${ }^{3}$ by the presence of unsuspected minute traces of copper, yet the experiments on mutual antagonisms contained therein are still valid and valuable, as demonstrated later by Ringer himself (see footnote, p. iii).

In addition to the pioneer work which chiefly forms the subject matter of this sketch of Ringer's scientific labours, he published a text-book of therapeutics which ran through many editions, and from its originality of treatment denoted a scientific aspect of mind towards medicine somewhat rare at that time. His contributions to pathology and medicine are chiefly to be found in the pages of the Practitioner, as also more popular expositions of his bio-chemical researches. A biographical notice of Ringer's career, and of his work as a clinician, will be found in the British Medical Journal, October 29th, 1910, p. 1384.

\section{BENJAMIN MOORE.}

December, 1910.

1. Journ. of Physiology, Vol. XVI, p. 1, 1894.

2. Ibid., Vol. XVII, p. 423, 1895.

3. Ibid., Vol XVIII, p. 319, 1895. 